\title{
Reduced Metabolic Response of the Aged Rat Brain to Haloperidol
}

\author{
GILBERTO PIZZOLATO, ${ }^{2}$ TIMOTHY T. SONCRANT, ${ }^{3}$ HAROLD W. HOLLOWAY, AND \\ STANLEY I. RAPOPORT
}

Laboratory of Neurosciences, National Institute on Aging, National Institutes of Health, Bethesda, Maryland 20205

\begin{abstract}
Local cerebral glucose utilization (LCGU) was determined in 49 brain regions of 3-, 12-, 24-, and 33-month-old awake Fischer-344 rats, at 30 to 120 min after administration of the dopaminergic antagonist haloperidol (HAL) at $1 \mathrm{mg} / \mathrm{kg}$ (i.p.). The quantitative autoradiographic $\left[{ }^{14} \mathrm{C}\right]$-2-deoxyglucose technique was employed. In 3-month rats, HAL produced statistically significant $(p<0.05$ ) reductions in LCGU in $63 \%$ of the brain regions examined, including those having dopaminergic as well as non-dopaminergic function. With increasing age, LCGU was progressively less affected by HAL. Significant declines in LCGU occurred in 21 to $23 \%$ of the observed regions in 12- and 24-month rats, and in $10 \%$ of the 49 regions in 33-month-old rats. The peak effects of HAL on LCGU occurred later in the 33-month- than in the 3-monthold rats (90 and $60 \mathrm{~min}$ after $\mathrm{HAL}$, respectively). The behavioral effect (catalepsy) of HAL was less in old than in young rats. Age-related differences in the cerebral metabolic and behavioral responsivities of rats to HAL are not due to differences in brain concentrations of HAL, as higher concentrations are obtained in older animals (Kapetanovic, I. M., D. J. Sweeney, and S. I. Rapoport (1982) J. Pharmacol. Exp. Ther. 221: 434-438). The differences correlate with known agedependent structural and biochemical deficits of the central dopaminergic system and indicate reduced functioning of that system in the rat brain after 12 months of age.
\end{abstract}

Aging is associated with altered neurotransmission in the brains of humans and animals (Roth and Hess, 1982; Severson et al., 1982). Markers for the dopaminergic system decrease progressively with age in the brain of several animal species (Pradhan, 1980). In rats, there are age-correlated reductions of brain tyrosine hydroxylase activity, of the rate of dopamine (DA) synthesis, and of brain concentrations of DA and of its metabolites (Reis et al., 1977; Ponzio et al., 1982; Algeri et al., 1983). The number of DA receptors is reduced in older rats, with a loss of about $40 \%$ in animals aged 24 months and older, compared to 3- to 5-month-old rats (Misra et al., 1980; Juseph el al., 1981; Govoni et al., 1983).

Human and animal studies report age-related differences in response to centrally acting drugs (Dawson-Butterworth, 1970; Castelden and George, 1979; Altamura et al., 1983). An increased

Received April 16, 1984; Revised March 25, 1985;

Accepted April 3, 1985

\footnotetext{
${ }^{1}$ We thank D. Larson for excellent technical assistance

${ }^{2}$ Present address: Clinica delle Malattie Nervose e Mentali, University of Padua, Italy

${ }^{3}$ To whom correspondence and reprint requests should be addressed, at Laboratory of Neurosciences, National Institute on Aging. National Institutes of Health, Clinical Center 10-6C103, Bethesda, MD 20205
}

cataleptic effect of haloperidol (HAL) (Campbell and Baldessarini, 1981) and greater stereotypic behavior after DA agonists (Smith et al., 1978) were described in old rats. However, less stereotypic sniffing followed intrastriatal amphetamine or DA injection in old than in young rats (Joseph and Roth, 1983). Furthermore, aged rodents responded less to conditions that require functional adaptations of the DA system. After electroconvulsive shock or exposure to cold, DA turnover increased less in old than in young rats (McNamara et al., 1977; Algeri et al., 1982). Neither behavioral supersensitivity nor increased DA receptor number was observed in old mice after chronic HAL administration (Randall et al., 1981).

in this study, we wanted to determine whether a reduced capacity to respond to a DA antagonist accompanies the reported structural and biochemical changes in the central DA system during aging in rats. We measured local cerebral glucose utilization (LCGU), a parameter of neuronal functional activity, using the $\left[{ }^{14} \mathrm{C}\right]$ deoxy-Dglucose $\left(\left[{ }^{14} \mathrm{C}\right] \mathrm{DG}\right)$ method of Sokoloff et al. (1977). We administered the DA receptor antagonist HAL $(1 \mathrm{mg} / \mathrm{kg})$ to awake Fischer-344 rats aged $3,12,24$, or 33 months. Fischer-344 rats reach maturity by 3 months of age and their median survival is 22 to 29 months; less than 1\% live to 33 months (Chesky and Rockstein, 1976; Coleman et al., 1977). In the rat, brain DA receptor number reaches adult levels during the first 2 months of life (Bruinink et al., 1983; Karakiulakis et al., 1983). We also quantified the cataleptic effect of HAL in 3- and 33-month-old rats.

Effects of HAL on LCGU in young mature rats have been investigated previously (McCulloch et al., 1982; Pizzolato et al., 1984). $H A L$ reduced LCGU in a dose- and time-dependent manner in brain regions that comprise DA pathways, and also in many other areas that do not posscss DA rccoptors. These responses to $\mathrm{H} \wedge \mathrm{L}$ result from its antagonism of DA receptors (Creese et al., 1976) and also can influence non-DA regions by connecting pathways.

Kapetanovic et al. (1982) examined the peripheral pharmacokinetics and time-dependent brain concentrations of $\mathrm{HAL}$ after its acute administration intraperitoneally to awake Fischer-344 rats aged 3 to 34 months. Plasma clearance of HAL was reduced in old animals, resulting in higher plasma and brain concentrations of HAL in 32- to 34-month versus 3- to 4-month rats for a given dose per kilogram of weight.

In the present study we found lesser effects of HAL in old than in young rats on two measures of brain functional activity: brain glucose utilization and behavior. The declines are not due to changes in the pharmacokinetics of HAL with age, however, because brain concentrations of HAL are higher in the old rats (Kapetanovic et al., 1982). They reflect, therefore, reduced function of the central DA system during aging.

\section{Materials and Methods}

Experiments were performed on awake, male Fischer-344 rats, $3,12,24$, and 3.3 months old, obtained from Charles River Breeding 1 aboratories (Wilmington, MA). $\left[{ }^{14} \mathrm{C}\right] \mathrm{DG}$ (specific activity, 50 to $55 \mathrm{mCi} / \mathrm{mmol}$ ) was 
purchased from New England Nuclear (Boston, MA) and was rechromatographed to ascertain purity. HAL was a gift from McNeil Pharmaceuticals (Spring House, PA)

\section{Preparation of animals}

Animals had free access to food and water until the morning of the experiment. After insertion of femoral vein and artery catheters under ether anesthesia, the rats were restrained in a plaster cast that enabled them to move their heads and forequarters only, and were allowed to recover from anesthesia for $5.5 \mathrm{hr}$ in a temperature-controlled enclosure before intravenous injection of $\left[{ }^{14} \mathrm{C}\right] \mathrm{DG}$. Body temperature was maintained at 35 to $36^{\circ} \mathrm{C}$ with a rectal thermoprobe connected to a feedback device that could activate an external heating element.

\section{Drug treatments}

Four to six rats were assigned to each of 15 treatment groups. They received the vehicle solution $(0.1 \mathrm{M}$ acetic acid) or HAL $(1 \mathrm{mg} / \mathrm{kg}(1 \mathrm{ml} / \mathrm{kg})$, i.p.) at 30 to $120 \mathrm{~min}$ before $\left[{ }^{14} \mathrm{C}\right] \mathrm{DG}$.

Three-month-old rats. Control animals received the vehicle solution at 30 to 90 min before $\left[{ }^{14} \mathrm{C}\right] \mathrm{DG}$; drug-treated rats were administered $\mathrm{HAL}$ at 30 , 60 or $90 \mathrm{~min}$ before $\left[{ }^{14} \mathrm{C}\right] \mathrm{DG}$.

Twelve- and 24-month-old rats. Control rats of these ages were injected with the vehicle solution at 60 to $90 \mathrm{~min}$ before $\left[{ }^{14} \mathrm{C}\right] \mathrm{DG}$; HAL injection was pertormed at 60 or $90 \mathrm{~min}$ before $\left[{ }^{14} \mathrm{C}\right] \mathrm{DG}$.

Thirty-three-month-old rats. Control rats received the vehicle at 30 to 120 min before $\left[{ }^{14} \mathrm{C}\right] \mathrm{DG}$; four treatment groups received HAL at $30,60,90$, or $120 \mathrm{~min}$ before $\left[{ }^{14} \mathrm{C}\right] \mathrm{DG}$

\section{Physiological assessments}

Arterial blood pressure, heart rate, and body temperature were monitored throughout the experiment. Blood pressure and heart rate were recorded from the femoral artery catheter connected to a strain-gauge transducer (Statham Instruments Co., Hatorey, Puerto Rico), which was attached to a paper chart recorder (model 2200, Gould Inc., Cleveland, $\mathrm{OH}$ ). Arterial $\mathrm{pH}$ $\mathrm{PaO}_{2}$ and $\mathrm{PaCO}_{2}$ were determined $(\mathrm{pH}-\mathrm{Blood}$ Gas Analyzer No. 1301, Instrumentation Laboratory, Lexington, MA) in $120 \mu$ lof arterial blood samples taken from each rat at 3 min before intravenous injection of $\left[{ }^{14} \mathrm{C}\right] \mathrm{DG}$.

\section{Behavioral observations}

Catalepsy was evaluated in 3-and 33-month-old animals at 15-min intervals after $\mathrm{HAL}$ or vehicle injection, and was scored on a four-point scale from 0 (no effect, animal normal) to 4 (animal completely cataleptic), as previously described (Pizzolato et al., 1984). Measures of catalepsy were: presence and intensity of reduced spontaneous movements of the head and forelimbs; hypertonic-akinetic posture with kyphotic trunk, extended head, broad-based support, up-turned tail; resistance and bracing to imposed horizontal displacement of the forequarters; and ptosis. All catalepsy determinations were made by a single rater (G. $P$.)

\section{Determination of LCGU}

LCGU was determined after a bolus injection of $\left[{ }^{14} \mathrm{C}\right] \mathrm{DG}(125 \mu \mathrm{Ci} / \mathrm{kg}$ of body weight, i.v.). Fourteen timed arterial blood samples were collected during the subsequent $50 \mathrm{~min}$ and were centrifuged. Aliquots of plasma were taken for assessment of glucose (Glucose Analyzer II. Beckman Instruments, Irvine, CA) and of $\left[{ }^{14} \mathrm{C}\right] \mathrm{DG}$ (model LS9000 Liquid Scintillation Spectrometer, Beckman).

Rats were killed $50 \mathrm{~min}$ after injection of $\left[{ }^{14} \mathrm{C}\right] \mathrm{DG}$ by an intravenous overdose of sodium pentobarbital. The brains were removed rapidly and frozen in 2-methylbutane cooled to $-40^{\circ} \mathrm{C}$. Coronal sections $(20 \mu \mathrm{m}$ thick) were obtained with a cryostat/microtome (Bright model 5030. Hacker Instruments, Fairfield, $\mathrm{N} J$ ) maintained at $-20^{\circ} \mathrm{C}$. Autoradiographs were made by exposing SB-5 x-ray films (Eastman Kodak Co., Rochester, NY) to the sections, and to methylmethacrylate standards of known ${ }^{14} \mathrm{C}$ concentration, for 7 days.

Radioactivity in brain regions was determined by quantitative autoradiography. Optical densities of autoradiograms were measured with a microdensitometer (model 700-10-90, Gamma Scientific, San Diego, CA) with a 100 $\mu \mathrm{m}$ diameter aperture. Six separate determinations were made at each region in both left and right sides of the brain, and the means for the two sides were averaged. Anatomical regions were identified by comparing autoradiograms with atlases of the rat brain (Konig and Klippel, 1967; Paxinos and Watson, 1982) and, where necessary, with cresyl violet-stained sections taken adjacent to those used for autoradiography. LCGU was calculated from brain and plasma radioactivities and from plasma glucose concentrations, using equations and constants given by Sokoloff et al. (1977).

\section{Statistical analysis}

Statistical significance was determined by one-way analysis of variance and Bonferroni's multiple comparison test (Miller, 1966). LCGU values for each group were normalized to age-matched control values. For each region, LCGU in HAL-treated rats at the time of peak metabolic effect $(60 \mathrm{~min}$ after HAL in 3-, 12-, and 24-month rats; 90 min after HAL in 33-month rats) was compared to LCGU in age-matched controls. Using normalized LCGU values determined at the time of peak effect of HAL, 12-, 24- and 33-month groups were compared to 3 -month-old animals. Statistical significance was taken as $p<0.05$

\section{Results}

\section{Physiological parameters}

After HAL (1 mg/kg, i.p.), no statistically significant changes were observed in budy lemperature, blood pressure, arterial blood gases, or $\mathrm{pH}$ at any age. Heart rate was reduced significantly (by $18 \%$ ) only at $30 \mathrm{~min}$ after $\mathrm{HAL}$ in 3 -month-old rats. $\mathrm{HAL}(1 \mathrm{mg} / \mathrm{kg})$ increased plasma glucose concentrations in 3-, 12-, and 24-monthold animals. However, increases in plasma glucose were progressively smaller with increasing age (significant elevations of about $50 \%$ were observed at 30 and 60 min after $\mathrm{HAL}$ in 3-month rats, $42 \%$ at 90 min after HAL in 12-month rats, and $29 \%$ at 60 min after HAL in 24-month-old rats). No significant change in plasma glucose was observed in 33-month-old animals after HAL administration. The $\left[{ }^{14} \mathrm{C}\right] \mathrm{DG}$ model accounts for variations in plasma glucose levels between 100 and $300 \mathrm{mg} / \mathrm{dl}$, without adjusting the lumped constant (Sokoloff, 1982).

\section{Behavior}

The time courses of catalepsy after HAL (1 mg/kg, i.p.) in 3- and 33-month rats are shown in Figure 1. The peak behavioral effect was significantly smaller in the aged animals (mean score, $2.78 \pm$ 0.17 (SEM)) than in the young ones (mean score, $3.50 \pm 0.21$ ). In the old rats the maximal behavioral effect also was delayed. Catalepsy was first observed in 3-month rats at 15 min after HAL administration and reached the peak level at $45 \mathrm{~min}$. In the 33month-old animals, catalepsy was minimal during the first hour and

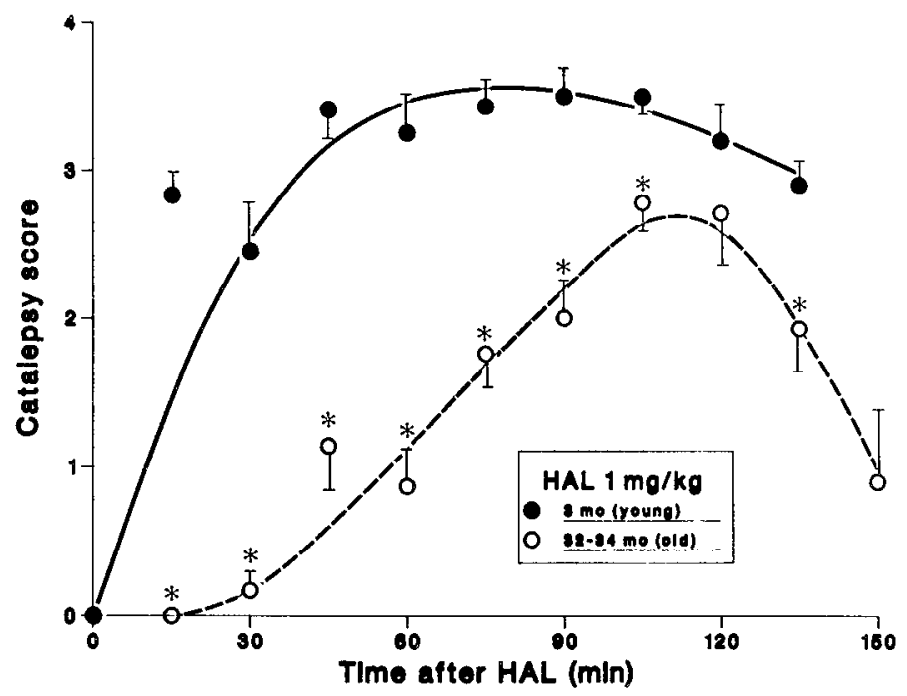

Figure 1. HAL-induced catalepsy. Catalepsy was determined in 3-month (Q) and 33-mo (O) rats at 15-min intervals after administration of HAL (1 mg/ $\mathrm{kg}$, i.p.). Scoring was on a scale of 0 (no effect) to 4 (completely cataleptic) Vertical bars indicate SEM; * indicates a significant difference between the mean scores for the two age groups at each time point $(p<0.05)$. 
peaked at 105 min after HAL. Catalepsy was not seen in vehicletreated animals.

\section{Local cerebral glucose utilization}

LCGU was determined in 49 brain regions at 30,60 , and 90 min after intraperitoneal injection of $\mathrm{HAL}(1 \mathrm{mg} / \mathrm{kg})$ in 3 month rats, at 60 and 90 min after HAL in 12- and 24-month-old rats, and at 30 , 60,90 , and 120 min after HAL in 33-month-old rats. The time of vehicle injection had no significant effect on LCGU in control rats of any age; therefore, these animals were combined into four groups: $3,12,24$, and 33 months control.

LCGU in gray and white matter regions was lower by about $20 \%$ in control 33-month compared to control 3-month animals (Table I). Average LCGU ( \pm SEM) for all of the regions examined was $83.8 \pm$ 1.6 for 3 -month-, $83.7 \pm 1.3$ for 12 -month-, $83.3 \pm 2.4$ for 24 . month-, and $65.9 \pm 2.6$ for 33-month-old rats. Age-related declines in LCGU, measured with the $\left[{ }^{14} \mathrm{C}\right] \mathrm{DG}$ method, have been reported in untreated male rats (Smith et al., 1980; London et al., 1981). Most of these declines reflect a reduction in the lumped constant for $\left[{ }^{14} \mathrm{C}\right]$ DG during aging in the rat (Rapoport, 1983) and, thus, are artifactual.

Time course of effect of HAL on LCGU. The general time course of the effect of HAL (1 mg/kg, i.p.) on LCGU for each of the four age groups is shown in Figure 2. As we reported previously (Pizzolato et al., 1984), in 3-month-old rats, HAL (1 mg/kg, i.p.) significantly reduced LCGU in only a few regions at 30 min after administration, whereas it produced its maximal reductions at $60 \mathrm{~min}$. At $60 \mathrm{~min}$, LCGU was significantly reduced in $63 \%$ of the regions examined, by an average of $21.7 \%$ for all of the regions. In 3-month-old animals, LCGU returned to near pre-drug levels in most regions at $90 \mathrm{~min}$ after HAL (average LCGU decline for all examined regions was $4.7 \%$ ). A similar pattern was observed in 12- and 24-month-old rats, in which the maximal response to $\mathrm{HAL}$ was at 60 min after treatment (significant declines were found in $23 \%$ and $21 \%$ of the regions examined, respectively). The time course of the cerebral metabolic effects of HAL was different in 33-month-old rats, however. In these animals no significant declines in LCGU wcre observed at 30 and 60 min after HAL, but a peak metabolic effect occurred at 90 min, when LCGU in $10 \%$ of the regions was reduced significantly (overall mean reduction $7.8 \%$ ). At 120 min after $\mathrm{HAL}$, no significant reductions were observed in any brain region of 33-month rats.

It was reported previously that LCGU returns to near-control levels shortly after the peak effect of HAL (Pizzolato et al., 1984). Because this recovery is not due to a decrease in DA receptor blockade (Kuhar et al., 1978), it was ascribed to compensatory mechanisms such as formation of new receptors or altered rates of DA turnover (Moleman et al., 1978; Meller et al., 1980).

Maximal age-dependent decline in LCGU. Table II shows LCGU values for 49 brain regions after HAL administration, expressed as percentage of age-matched control values, at the time of the maximal metabolic effect of HAL $(1 \mathrm{mg} / \mathrm{kg}$, i.p.). The time points are at 60

TABLE I

Local cerebral glucose utilization after haloperidol in some brain regions of awake Fischer-344 rats

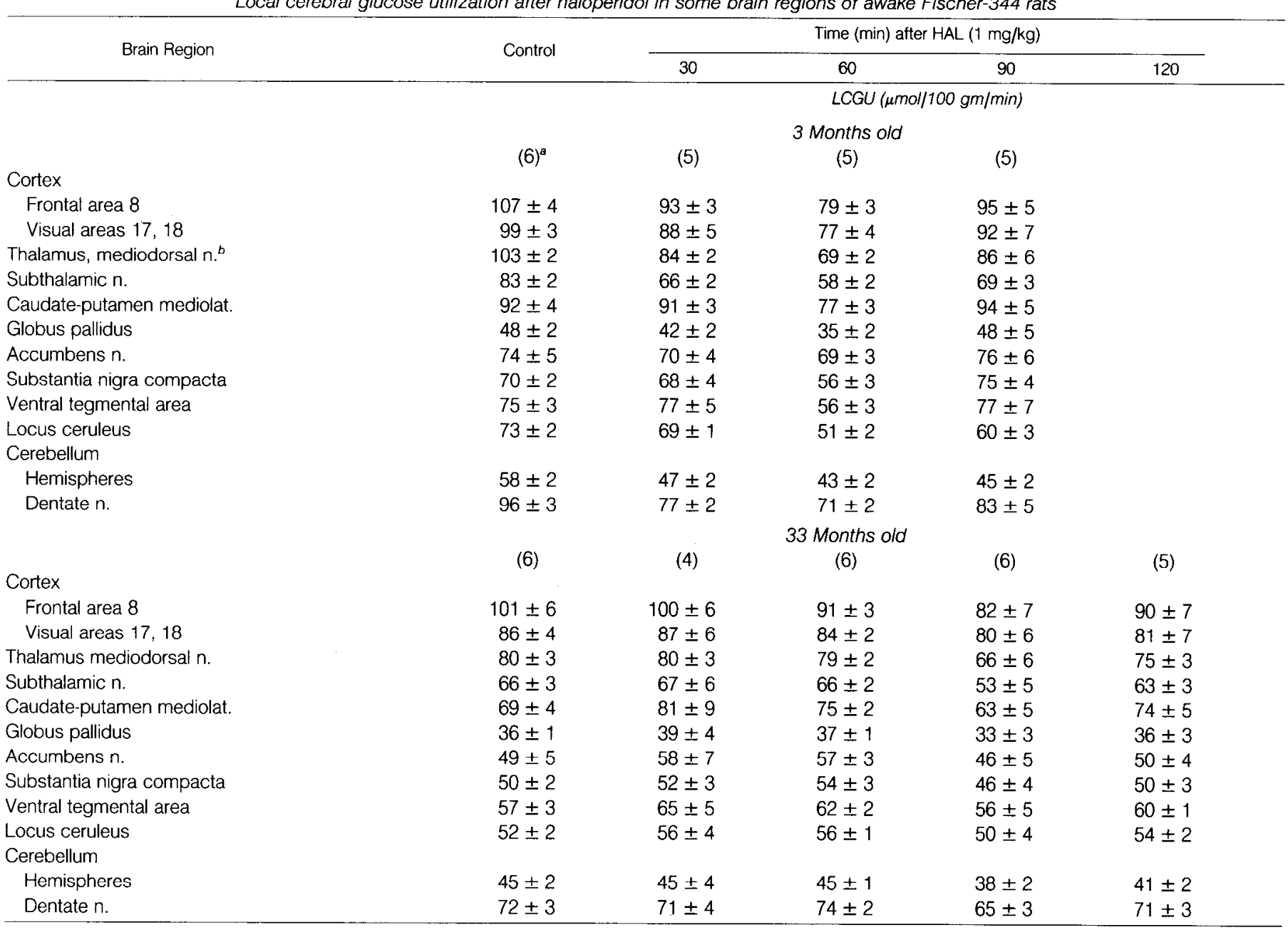

a Values are mean \pm SEM for the number of animals shown in parentheses.

${ }^{b}$ n., nucleus; mediolat., mediolateral. 


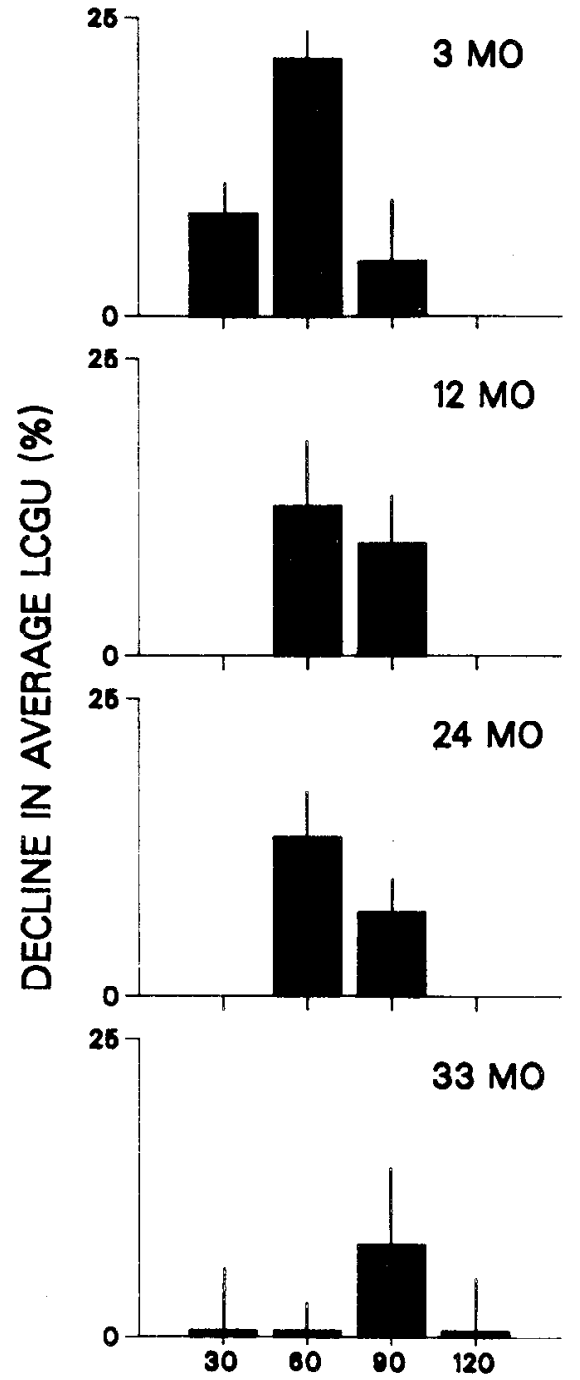

MIN AFTER HAL

Figure 2. Effect of HAL on local cerebral glucose utilization. LCGU was measurcd in 49 brain regions at 30 to $120 \mathrm{~min}$ after $\mathrm{HAL}(1 \mathrm{mg} / \mathrm{kg}$, i.p.) in Fischer-344 rats of four ages: $3,12,24$, and 33 months. Percentage reductions from control of mean LCGU for all regions are shown. Narrow vertical burs indicate SEM.

min after HAL for 3-, 12-, and 24-mo-old rats, and at 90 min after $\mathrm{HAL}$ for 33-month-old animals. LCGU values for control and HAL (1 $\mathrm{mg} / \mathrm{kg}$ )-treated 3-month-old rats have been reported previously ( $\mathrm{Piz}$ zolato et al., 1984). Metabolic rates at other times are not tabulated because few differences from control values were found.

The maximal effect of HAL (1 mg/kg, i.p.) on LCGU declined in relation to age. The number of brain regions in which HAL significantly reduced LCGU fell from $63 \%$ of the regions examined in 3 month rats, to 21 to $23 \%$ of 12 - and 24 -month-rats, and to only $10 \%$ of 33-month rats. Also, the reduction in the overall mean LCGU in all regions examined was progressively less in older arimals. Mean LCGU fell by $21.7 \%$ after HAL in 3-month rats, by $13 \%$ in 12 - and 24 -month rats, and by $7.8 \%$ in 33 -month rats.

The pattern of age-related reductions in the average metabolic response to HAL was apparent also in most of the individual regions examined. Figure 3 depicts the age-dependent decline in the LCGU response to HAL for several representative brain regions.

Regional distribution of LCGU response to HAL. In 3-month-old rats, HAL (1 mg/kg) produced widespread reductions in LCGU (Fig. 4). Significant decreases were observed in regions containing DA neurons or terminals (e.g., caudate-putamen, globus pallidus, ventral tegmental area, precentral medial cortex) and also in many other regions not known to contain DA terminals or receptors (e.g., most neocortical, cerebellar, and brainstem regions) (Burt et al., 1976; Beckstead et al., 1979). Significant reductions of LCGU after HAL were seen in only a few brain regions of 33-month rals: frontal cortex, mediodorsal thalamus, subthalamic nucleus, and cerebellar hemispheres. The lateral habenula was the only region in which HAL produced a large elevation in LCGU, and this was observed at all time points at each age.

\section{Discussion}

These results show that metabolic sensitivity of the brain of male Fischer-344 rats to the DA antagonist HAL decreases progressively with age after maturity. In 3-month rats, HAL (1 mg/kg) produced widespread reductions of LCGU $(63 \%$ of the regions; overall mean decline, $21.7 \%$ ). In 33 -month-old rats, only $10 \%$ of the regions were significantly affected by $\mathrm{HAL}$, and the overall mean decline was $7.8 \%$. The 12 - and 24-month-old animals showed an intermediate response to HAL, indicating that sensitivity to HAL lalls progressively throughout maturity.

The maximal catalepsy score also was less in 33-month-old than in 3-month-old rats. The metabolic and behavioral responses also occurred later after HAL administration in the 33-month than in the 3-month-old rats. These findings support the close relation between changes in cerebral metabolism and behavior that we observed also after the DA agonist bromocriptine (Pizzolato et al., 1985a) and after acute and chronic HAL (Pizzolato et al., 1984, 1985b) in 3-monthold rats. The findings are consistent with the reported reduced LCGU response of the aged rat brain to the DA agonist apomorphine (Smith, 1981)

Pharmacokinetic differences do not account for reduced cerebral metabolic and behavioral responses to HAL in the aged rat. Brain concentrations of HAL in 3- to 4-month and 32- to 34-month-old Fischer-344 rats are similar at $30 \mathrm{~min}$ after an acute intraperitoneal injection of the same dose of the drug, but at 60 min and later, they are higher in aged animals because of reduced plasma clearance of HAL (Kapetanovic et al., 1982). Reduced sensitivity to HAL, therefore, occurs despite higher brain levels of the drug

The diminishing effect of HAL on LCGU and on behavior in old rats may be associated with age-dependent, progressive deficits in DA neurotransmission. The activity of tyrosine hydroxylase, the ratelimiting enzyme for DA synthesis, is decreased in the aged rat brain (Reis et al., 1977). Concentrations of DA and of its metabolites in DA regions show progressive, statistically age-correlated declines in rats (Ponzio et al., 1982; Algeri et al., 1983). DA sensitivity of striatal adenylate cyclase is reduced at 12 and 24-months, compared to 4 months, and is abolished in 30-month-old animals (Puri and Volicer, 1977). A decreased density of DA receptors has been reported in several brain areas of aged rats (Memo et al., 1980; Misra et al., 1980), mice (Severson and Finch, 1980), rabbits (Thal et al., 1980), and humans (Severson et al., 1982), although the affinity of DA receptors for dopaminergic ligands is not altered (Misra et al., 1980). Decreases in DA receptor number, which occur in rodents before midlife (Severson and Finch, 1980), progress to 30 to $50 \%$ of 3- to 5 -month values in rats 24 months and older (Joseph et al., 1981; De Blasi et al., 1982). This may be due to reduced rates of synthesis of DA receptors in old animals (Henry and Roth, 1984). As the primary sites of action of HAL are central DA receptors (Creese et al., 1976), age-related changes in DA receptor number and in post-receptor mechanisms, such as adenylate cyclase activity, may contribute to the reduced responsivity of the aged brain to HAL.

Losses of functional interconnections in the aged brain also may contribute to the less widespread effect of HAL in the aged rat. In 3-month-old rats. HAL reduced LCGU in DA regions as well as nonDA regions (Fig. 4) (Burt et al., 1976; Beckstead et al., 1979; Simon et al., 1979). Significant decreases were found in all neocortical and 
TABLE \|

Effect of haloperidol (1 $\mathrm{mg} / \mathrm{kg}$, i.p.) on cerebral glucose utilization in awake Fischer-344 rats of different ages

\begin{tabular}{cccc}
\multicolumn{4}{c}{ Rat Age (months)/Time after Treatment (min) } \\
\hline 3 & 12 & 24 & 33 \\
60 & 60 & 60 & 90 \\
$(5)^{a}$ & $(5)$ & $(5)$ & $(6)$
\end{tabular}

Cortical regions

Frontal area 8 (layer IV)

Frontal area (layer IV)

Pyriform area $51 \mathrm{~B}$

Somatosensory (layer IV)

Auditory area 41 (layer IV)

Visual areas 17, 18 (layer IV)

Limbic regions

Precentral medial cortex

Precentral agranular

Entorhinal cortex lateral

Dorsal hippocampus

CA1

CA3

Dentate gyrus

Lateral amygdala

Lateral septum

Diagonal band $n{ }^{\circ}$

Olfactory tubercle

Lateral preoptic area

Preoptic magnocellular $\mathbf{n}$.

Medial forebrain bundle

Anterior commissure

Diencephalon

Thalamus, mediodorsal $n$.

Thalamus, ventromedial $n$.

Lateral habenula

Subthalamic $\mathrm{n}$.

Posterior hypothalamus

Hypothalamic arcuate $n$.

Lateral hypothalamic $n$.

Medial geniculate

Lateral geniculate

Basal ganglia

Globus pallidus

Caudate-putamen

anterior

mediolateral

mediomedial

posterior

Accumbens $\mathrm{n}$.

Brainstem

Substantia nigra

pars compacta

pars reticulata

Ventral tegmental area

Raphe dorsal

Raphe median

Superior colliculus

Inferior colliculus

Locus ceruleus

Superior olive

Inferior olive

Cerebellum

Vermis

Hemispheres

Interpositus $\mathrm{n}$.

Dentate $\mathrm{n}$.

\begin{tabular}{|c|c|c|c|}
\hline $74 \pm 2^{b}$ & $77 \pm 4^{b}$ & $82 \pm 3^{b}$ & $80 \pm 5^{b}$ \\
\hline $75 \pm 4^{b}$ & $77 \pm 6^{b}$ & $80 \pm 5$ & $93 \pm 8$ \\
\hline $82 \pm 2$ & $81 \pm 7$ & $90 \pm 6$ & $93 \pm 8$ \\
\hline $75 \pm 3^{b}$ & $85 \pm 7$ & $86 \pm 4$ & $86 \pm 7$ \\
\hline $67 \pm 4^{b}$ & $81 \pm 4$ & $84 \pm 3$ & $91 \pm 8^{c}$ \\
\hline $78 \pm 4^{b}$ & $78 \pm 6^{b}$ & $74 \pm 5^{b}$ & $93 \pm 7$ \\
\hline $76 \pm 3^{b}$ & $81 \pm 5$ & $88 \pm 4$ & $85 \pm 5$ \\
\hline $72 \pm 5^{b}$ & $80 \pm 4$ & $84 \pm 3$ & $84 \pm 7$ \\
\hline $82 \pm 3$ & $82 \pm 5$ & $83 \pm 8$ & $88 \pm 7$ \\
\hline $74 \pm 5^{b}$ & $80 \pm 8$ & $84 \pm 6$ & $95 \pm 9$ \\
\hline $66 \pm 3^{b}$ & $77 \pm 6$ & $89 \pm 7$ & $91 \pm 7$ \\
\hline $73 \pm 4^{b}$ & $78 \pm 6$ & $89 \pm 5$ & $92 \pm 8$ \\
\hline $76 \pm 4^{b}$ & $89 \pm 8$ & $85 \pm 4$ & $80 \pm 6^{b}$ \\
\hline $75 \pm 7^{b}$ & $89 \pm 7$ & $90 \pm 7$ & $83 \pm 7$ \\
\hline $83 \pm 5$ & $93 \pm 8$ & $85 \pm 5$ & $92 \pm 9$ \\
\hline $89 \pm 4$ & $78 \pm 7$ & $88 \pm 7$ & $101 \pm 8$ \\
\hline $85 \pm 5$ & $87 \pm 4$ & $84 \pm 5$ & $99 \pm 8$ \\
\hline $75 \pm 4^{b}$ & $79 \pm 5^{b}$ & $75 \pm 3^{b}$ & $88 \pm 7$ \\
\hline $73 \pm 5$ & $105 \pm 6$ & $89 \pm 4$ & $92 \pm 10$ \\
\hline $59 \pm 5^{h}$ & $68 \pm 9^{h}$ & $74 \pm 7$ & $84 \pm 6$ \\
\hline $68 \pm 2^{b}$ & $79 \pm 3^{b}$ & $81 \pm 3^{b}$ & $83 \pm 7^{b}$ \\
\hline $69 \pm 3^{b}$ & $91 \pm 7^{c}$ & $91 \pm 3^{c}$ & $93 \pm 8^{c}$ \\
\hline $137 \pm 8^{b}$ & $194 \pm 12^{b}$ & $167 \pm 9^{b}$ & $160 \pm 13$ \\
\hline $70 \pm 3^{D}$ & $76 \perp 5^{b}$ & $74 \pm 4^{b}$ & $80 \pm 8^{b}$ \\
\hline $72 \pm 4^{b}$ & $84 \pm 6$ & $82 \pm 4$ & $93 \pm 10$ \\
\hline $81 \pm 5$ & $83 \pm 7$ & $91 \pm 8$ & $106 \pm 14$ \\
\hline $82 \pm 8$ & $100 \pm 11$ & $91 \pm 5$ & $91 \pm 8$ \\
\hline $66 \pm 4^{b}$ & $82 \pm 4$ & $80 \pm 4$ & $92 \pm 10$ \\
\hline $82 \pm 3$ & $85 \pm 5$ & $76 \pm 5^{\circ}$ & $93 \pm 9$ \\
\hline $73 \pm 4^{b}$ & $89 \pm 9$ & $85 \pm 8$ & $90 \pm 8$ \\
\hline $80 \pm 5$ & $102 \pm 10$ & $98 \pm 4$ & $100 \pm 7$ \\
\hline $83 \pm 3$ & $85 \pm 8$ & $92 \pm 7$ & $91 \pm 7$ \\
\hline $75 \pm 4^{b}$ & $81 \pm 7$ & $89 \pm 5$ & $83 \pm 8$ \\
\hline $78 \pm 3$ & $91 \pm 6$ & $86 \pm 5$ & $93 \pm 9$ \\
\hline $93 \pm 4$ & $98 \pm 7$ & $99 \pm 5$ & $93 \pm 9$ \\
\hline
\end{tabular}

$80 \pm 5$

$87 \pm 6$

$86 \pm 7$

$75 \pm 6$
$75 \pm 3^{\circ}$

$77 \pm 5$

$79 \pm 3$

$91 \pm 3^{b}$

$71 \pm 4$

$84 \pm 6$

$70 \pm 4^{b}$

$92 \pm 4$

$83 \pm 6$

$80 \pm 4$

$87 \pm 9$

$70 \pm 2$

$72 \pm 5^{b}$

$81 \pm 5^{b}$

$91+5$

$78 \pm 7^{b}$

$93 \pm 8$

$82 \pm 8$

$99 \pm 9$

$77 \pm 7^{\circ}$

$74 \pm 4$

$88 \pm 3$

$66 \pm 4$

$74 \pm 3$

$74 \pm 4^{b}$

$91 \pm 4$

$86 \pm 7$

$85 \pm 7$

$85+5$

$\pm 6$

$97 \pm 12$

$97 \pm 7^{\circ}$

$98 \pm 3^{c}$

$99 \pm 7$

$70 \pm 3^{b}$

$74 \pm 3^{b}$

$82 \pm 3^{b}$

$81 \pm 5^{b}$

$83 \pm 5$

$79 \pm 4^{5}$

$91 \pm 4^{c}$

$74 \pm 2^{b}$

$91 \pm 6$

$75 \pm 3^{b}$

$83 \pm 5^{b}$

$92 \pm 6^{c}$

$91 \pm 4^{\circ}$

${ }^{a}$ Values are mean \pm SEM for the number of animals shown in parentheses.

${ }^{b}$ Significantly different from control mean $(p<0.05)$.

${ }^{c}$ Significantly different from LCGU percentage of 3-month-old rats $(p<0.05)$.

${ }^{d}$ n., nucleus. 


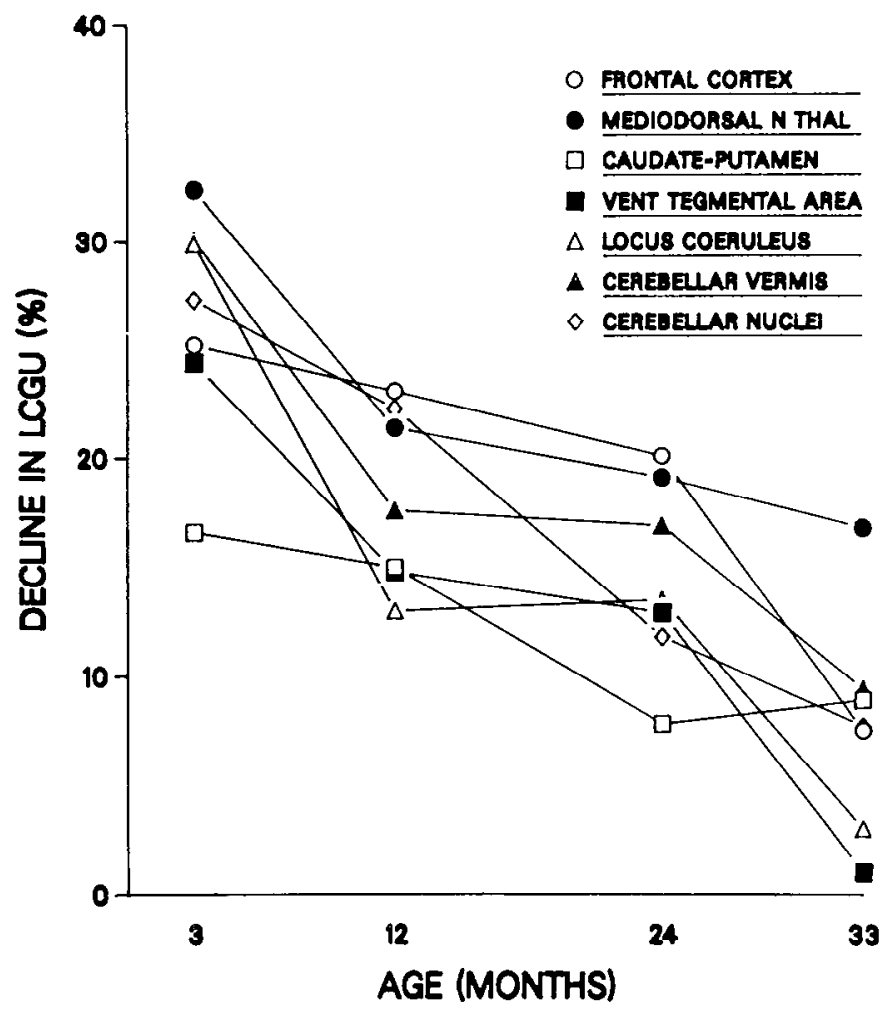

Higure 3. Percentage of decline of LCGU from control in rat brain regions after HAL. Percentages of declines of LCGU after HAL ( $1 \mathrm{mg} / \mathrm{kg}$, i.p.) in a representative group of brain regions of $3 \cdot, 12,24-$, and 33-month-old Fischer-344 rats, at the time of the maximal effect of HAL on LCGU, are shown.

cerebellar areas, of which only the frontal cortex possesses DA receptors (Thierry et al., 1973; Klemm et al., 1979). As we noted previously (Pizzolato et al., 1984), metabolic changes in non-DA regions after $\mathrm{HAL}$ may represent an indirect effect, mediated by non-DA pathways that are influenced by DA inputs. Age-related deficits in other neurotransmitter systems, such as the adrenergic (Enna and Strong, 1981; Misra et al., 1980), GABAergic (Govoni et al., 1980), and cholinergic (Morin and Westerlain, 1980; Strong et al., 1980) pathways, also could influence the reduction in the number of regions affected by HAL. A generalized age-related reduction in the anatomical complexity of neural circuits (Feldman, 1976; Rogers et al., 1984) may contribute to the decreased effect of HAL (and possibly of other drugs) in aged rats.

In this study, we found a striking reduction in the metabolic response of the aged rat brain to HAL. The deficit begins within the first third of the mature life span and becomes progressively more severe as the rat ages. The reduced response to HAL correlates with age-dependent losses of functional and biochemical components of the DA system that, in rodents, begin before midilife and progress with age. These deficits probably are related to reduced locomotor activity, rigidity, and impaired motor coordination and balance in senescent rats, and can be reversed by DA agonists or by induced production of new DA receptors (Marshall and Berrios, 1979; Joseph et al., 1983). In humans, biochemical and receptor markers for the DA system also decline progressively with age (Severson et al., 1982), and movement disorders occur in the elderly (akinesia and rigidity) that resemble those of Parkinson's disease, a syndrome of DA deficiency (Critchley, 1956; McGeer et al., 1977).

The loss of CNS DA elements in middle-aged humans is not accompanied by concurrent changes in motor behavior, possibly because of redundancy of DA pathways and compensatory adaptive changes in the central DA system. On the basis of studies in
A
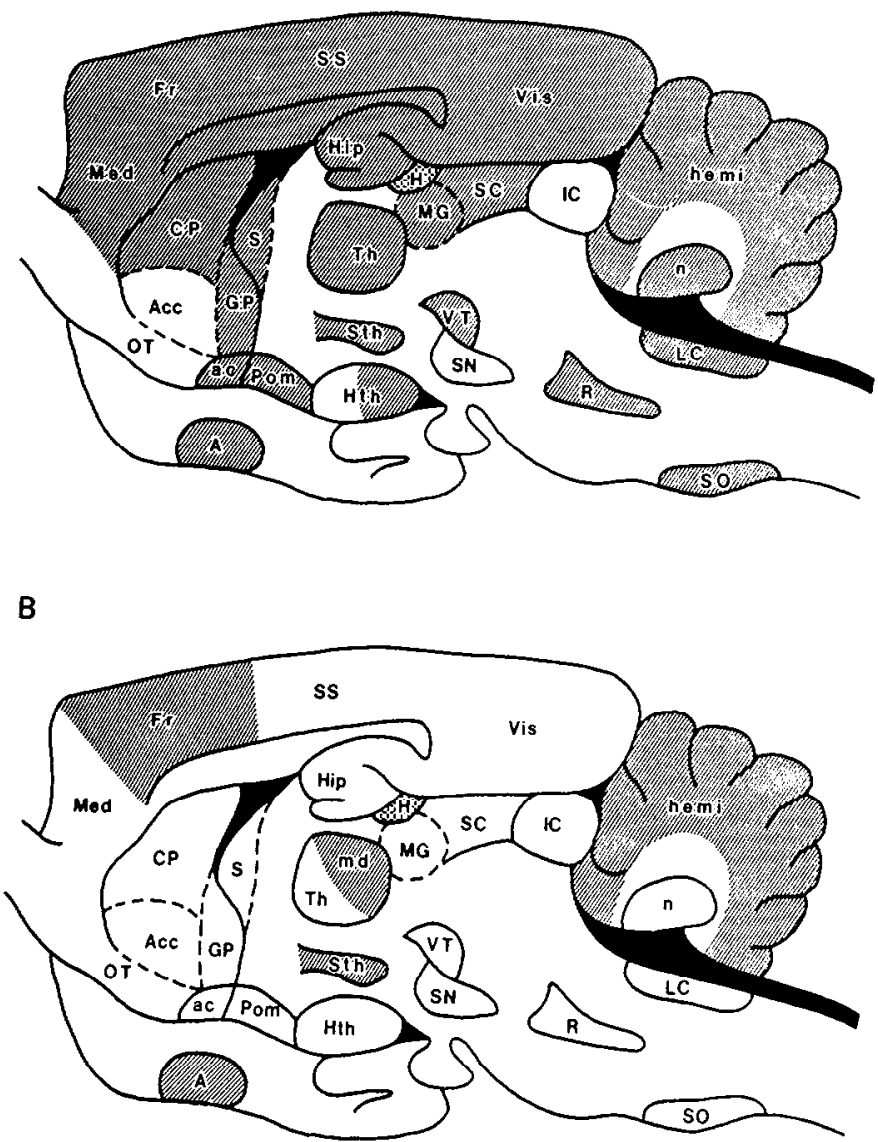

Figure 4. Anatomical patterns of LCGU responses to HAL in 3-month and 33-month-old rats. Regions in which LCGU was significantly decreased by HAl $(1 \mathrm{mg} / \mathrm{kg}$, i.p.) in 3-month $(A)$ - and 33-month $(B)$-old Fischer-344 rats are denoted by shaded areas. The lateral habenula was the only region in which HAL elevated LCGU. $A$, lateral amygdala; ac, anterior commissure; $A c c$, accumbens nucleus; $C P$, caudate-putamen; $F r$, frontal cortex; $G P$, globus pallidus; $H$, lateral habenula; hemi, cerebellar hemispheres; Hip, dorsal hippocampus; $H$ th , hypothalamus; $\mathcal{I}$, inferior colliculus; $L C$, locus ceruleus; $m d$, mediodorsal thalamic nucleus; Med, precentral medial cortex; $M G$, medial geniculate; $n$, cerebellar nuclei; OT, olfactory tubercle; Pom, preoptic magnocellular nucleus; $R$, dorsal raphe; $S$, lateral septum; $S C$, superior colliculus; $S N$, substantia nigra; SO, superior olive; SS, somatosensory cortex; Sth, subthalamic nucleus; Th, thalamus; Vis, visual cortex; $V T$, ventral tegmental area.

Parkinson's disease, it has been suggested that an $80 \%$ reduction in the number of DA nigrostriatal projections is required for the clinical symptoms to appear (Hornykiewicz, 1983). In healthy subjects, motor deficits become apparent only late in life, perhaps when adaptive mechanisms can compensate no longer for losses in the DA system.

Although functional metabolic deficits do not parallel the early degenerative changes of the DA system in resting animals, a reduced functional capacity at 12 and 24 months was demonstrated in this study by a pharmacologic challenge. Drug-induced alterations of the CNS may be useful in detecting early functional deficits in other brain systems during aging.

\section{References}

Algeri, S., G. Calderini, G. Lomuscio, G. Vantini, G. Toffano, and F. Ponzio (1982) Changes with age in rat central monoaminergic system responses to cold stress. Neurobiol. Aging 3: 237-242.

Algeri, S., G. Calderini, G. Toffano, and F. Ponzio (1983) Neurotransmitter 
alteralions in aging rals. In Aging of the Brain, D. Sannuel et al., eds., pp. 227-243, Raven Press, New York.

Altamura, A. C., T. Melorio, G. Invernizzi, F. Colacurcio, and R. Gomeni (1983) Age-related differences in kinetics and side-ettects of viloxazine in man and their clinical implications. Psychopharmacology 81: 281-285.

Beckstead, R. M., V. B. Domesick, and W. J. H. Nauta (1979) Efferent connections of the substantia nigra and ventral tegmental area in the rat. Brain Res. 175: 191-217.

Bruinink, A., W. Lichtensteiger, and M. Schlumpf (1983) Pre- and postnata ontogeny and characterization of dopaminergic $D_{2}$, serotonergic $S_{2}$, and spirodecanone binding sites in rat forebrain. J. Neurochem. 40: 12271236.

Burt, D. R., I. Creese, and S. H. Snyder (1976) Properties of [ $\left.{ }^{3} H\right]$ haloperidol and $\left[{ }^{3} \mathrm{H}\right]$ dopamine binding associated with dopamine receptors in calf brain membranes. Mol. Pharmacol. 12: 800-812

Campbell, A., and R. J. Baldessarini (1981) Effects of maturation and aging on behavioral responses to haloperidol in the rat. Psychopharmacology 73: 219-222.

Castelden, C. M., and C. F. George (1979) Increased sensitivity to benzodiazepines in the elderly. In Drugs and the Elderly, J. Crooks and I. $\mathrm{H}$ Stevenson, eds., pp. 169-178, Univeristy Park Press, Baltimore.

Chesky, J. A., and M. Rockstein (1976) Life span characteristics in the male Fischer rat. Exp. Aging Res. 2: 399-407.

Coleman, G. L., L. S. Barthold, G. W. Osbaldiston, S. J. Foster, and A. M Jones (1977) Pathological changes during aging in barrier-reared Fischer344 male rats. J. Gerontol. 32: 258-278.

Creese, I., D. R. Burt, and S. H. Snyder (1976) Dopamine receptor binding predicts clinical and pharmacological potencies of antischizophrenic drugs. Science 192: 481-483.

Critchley, M. (1956) Neurologic changes in the aged. J. Chronic Dis. 3: 459477.

Dawson-Butterworth, K. (1970) The chemophsychotherapeutics of geriatric sedation. J. Am. Geriatr. Soc. 18: 97-114.

De Blasi, A., S. Cotecchia, and T. Mennini (1982) Selective changes of receptor binding in brain regions of aged rat. Life Sci. 31: 335-340.

Enna, S. J., and R. Strong (1981) Age-related alterations in central nervous system neurotransmitter receptor binding. In Brain Neurotransmitters and Receptors in Aging, S. J. Enna, T. Samorajski, and B. Beer, eds., pp. 133-142, Raven Press, New York.

Feldman, M. L. (1976) Aging changes in the morphology of cortical dendrites Neurobiol. Aging 3: 211-227.

Govoni, S., M. Memo, L. Saiani, P. F. Spano, and M. Trabucchi (1980) Impairment of brain neurotransmitter receptors in aged rats. Mcch. Agcing Dev. 12: $39-46$

Govoni, S., M. Trabucchi, A. Bosio, and P. F. Spano (1983) Functional changes of neurotransmitter receptors in the brair of aged rals. Aging 21. 363-371.

Henry, J. M., and G. S. Roth (1984) Effect of aging on recovery of striatal dopamine receptors following $N$-ethoxycarbonyl-2-ethoxy-1,2-dihydroquinoline (EEDQ) blockade. Life Sci. 35: 899-904

Hornykiewicz, O. (1983) Dopamine changes in the aging human brain: Functional considerations. Aging 23: 9-14.

Joseph, J. A., and G. S. Roth (1983) Age-related alterations in dopaminergic mechanisms. In Aging of the Brain. D. Samuel et al., eds., pp. 245-256, Raven Press, New York.

Joseph, J. A., R. E. Berger, B. T. Engel, and G. S. Roth (1981) Age-related changes in the neostriatum: A behavioral and biochemical analysis. J. Gerontol. 33: 643-649

Joseph, J. A., R. T. Bartus, D. Clody, D. Morgan, C. Finch, B. Beer, and S. Sesack (1983) Psychomotor performance in the senescent rodent: Reduction of deficits via striatal dopamine receptor up-regulation. Neurobiol. Aging 4: 313-319

Kapetanovic, I. M., D. J. Sweeney, and S. I. Rapoport (1982) Age effects on haloperidol pharmacokinetics in male, Fischer-344 rats. J. Pharmacol. Exp. Ther. 221: 434-438

Karakiulakis, G., A. G. Paradelis, P. G. Papaioannidou, and P. J. Thomas (1983) Maturational aspects of the dopaminergic system: Ontogenesis of high affinity dopamine binding to neural membrane fragments of the rat brain. Methods Find. Exp. Clin. Pharmacol. 5: 685-694.

Klemm, N., L. C. Murrin, and M. J. Kuhar (1979) Neuroleptic and dopamine receptors: Autoradiographic localization of $\left[{ }^{3} \mathrm{H}\right]$ spiperone in rat brain. Brain Res. 169: 1-9.

Konig, J. F. R., and R. A. Klippel (1967) The Rat Brain-A Stereotaxic Atlas of the Forebrain and the Lower Parts of the Brainstem, Robert A. Krieger Publishing Co., Huntington, NY.
Kuhlar, M. J., C. Murrirn, A. T. Maloul, and N. Klermrn (1978) Doparmine receptors binding in vivo: The feasibility of autoradiographic studies. Life Sci. 22: 203-210.

London E. D., S. M. Nespor, M. Ohata, and S. I. Rapoport (1981) Loca cerebral glucose utilization during development and aging of the Fischer344 rat. J. Neurochem. 37: 217-221.

Marshall, J. F., and N. Berrios (1979) Movement disorders in aged rats: Reversal by dopamine receptor stimulation. Science 206: 477-479.

McCulloch, J., H. Savaki, and L. Sokoloff (1982) Distribution of effects of haloperidol on energy metabolism in the rat brain. Brain Res. 243: 81-90.

McGeer, P. L., E. G. McGeer, and J. S. Suzuki (1977) Aging and extrapyramidal function. Arch. Neurol. 31: 33-35.

McNamara, M. C., A. T. Miller, Jr., V. A. Beniguns, and J. N. Davis (1977) Age related changes in the effect of electroconvulsive shock (ECS) on the in vivo hydroxylation of tyrosine and tryptophan in rat brain. Brain Res. 131: $313-320$

Meller, E., A. J. Friedhoff, and E. Friedman (1980) Differential effects of acute and chronic haloperidol treatment on striatal and nigral 3,4-dihydroxyphenylacetic acid (DOPAC) levels. Life Sci. 26: 541-547.

Memo, M., L. Lucchi, P. F. Spano, and M. Trabucchi (1980) Aging process affects a single class of dopamine receptors. Brain Res. 202: 488-492.

Miller, R. G., Jr. (1966) Simultaneous Statistical Inference, pp. 76-81, McGraw-Hill, New York

Misra, C. H., H. S. Shelat, and R. C. Smith (1980) Effect of age on adrenergic and dopaminergic receptor binding in rat brain. Life Sci. 27: 521-526.

Moleman, P., J. Bruinsvels, and C. F. M. van Valkenburg (1978) On the relation between haloperidol-induced alterations in dopamine release and dopamine metabolism in rat striatum. Life Sci. 23: 611-616.

Morin, A. M., and C. G. Westerlain (1980) Ageing and rat brain muscarinic receptors as measured by quinuclidinyl benzilate binding. Neurochem Res. 5: 301-308

Paxinos G., and C. Watson (1982) The Rat Brain in Stereotaxic Coordinates, Academic Press, Inc., New York

Pizzolato, G., T. T. Soncrant, and S. I. Rapoport (1984) Haloperidol and cerebral metabolism in the conscious rat: Relation to pharmacokinetics. J. Neurochem. 43: 724-732.

Pizzolato, G., T. T. Soncrant, D. M. Larson, and S. I. Rapoport (1985a) Reduced metabolic response of the rat brain to haloperidol after chronic treatment. Brain Res. 337: 1-9.

Pizzolato, G., T. T. Soncrant, and S. I. Rapoport (1985b) Time-course and regional distribution of the metabolic effects of bromocriptine in the rat brain. Brain Res., in press.

Ponzio, F., G. Clderini, G. Lomuscio, G. Vantini, G. Toffano, and S. Algeri (1982) Changes in monoamines and their metabolite levels in some brain regions of aged rats. Neurobiol. Aging 3: 23-29.

Pradhan, S. N. (1980) Central neurotransmintters and aging. Lile Sci. 26. 1643-1656

Puri, S. K., and L. Volicer (1977) Effect of aging on cyclic AMP levels and adenylate cyclase and phosphodiesterase activities in the rat corpus striatum. Mech. Ageing Dev. 6: 53-58.

Randall, P. K., J. A. Severson, and C. B. Finch (1981) Aging and the regulation of striatal dopaminergic mechanisms in mice. J. Pharmacol. Exp. Ther. 219: 695-700

Rapoport S. I. (1983) Biological aspects of Alzheimer's disease, R. Katzman ed., Banbury Rep. 15: 329-334

Reis, D. J., R. A. Ross, and T. H. Joh (1977) Changes in the activity and amounts of enzymes synthesizing catecholamines and acetylcholine in brain, adrenal medulla, and sympathetic ganglia of aged rat and mouse. Brain Res. 136: 465-474

Rogers, J., S. F. Zornetzer, F. E. Bloom, and R. E. Mervis (1984) Senescent microstructural changes in rat cerebellum. Brain Res. 292: 23-32.

Roth, G. S., and G. D. Hess (1982) Changes in the mechanisms of hormone and neurotransmitter action during aging: Current status of the role of receptor and post-receptor alteration. A review. Mech. Ageing Dev. 20 175-194.

Severson, J. A, and C. E. Finch (1980) Reduced dopaminergic binding during ageing in the rodent striatum. Brain Res. 192: 147-162.

Severson, J. A., J. Marcusson, B. Winblad, and C. E. Finch (1982) Agecorrelated loss of dopaminergic binding sites in human basal ganglia. $J$. Neurochem. 39: 1623-1631.

Simon, H., M. Le Moal, and A. Calas (1979) Efferents and afferents of the ventral tegmental-A10 region studied after local injection of $\left[{ }^{3} \mathrm{H}\right]$ leucine and horseradish peroxidase. Brain Res. 178: 17-40.

Smith, C. B. (1981) Age-related changes in local rates of cerebral glucose utilization in the rat. Aging 17: 195-201. 
Smith, C. B., C. Goochee, S. I. Kapoport, and L. Sokoloff (1980) Effects of ageing on local rates of cerebral glucose utilization in the rat. Brain 103: $217-221$.

Smith, R. C., D. E. Leelavathi, and A. M. Lauritzen (1978) Behavioral effects of dopamine agonists increase with age. Commun. Psychopharmacol. 2: $39-43$.

Sokoloff, L. (1982) The radioactive deoxyglucose method: Theory, procedure, and applications for the measurement of local glucose utilization in the central nervous system. Adv. Neurochem. 4: 1-82.

Sokoloff, L., M. Reivich, C. Kennedy, M. H. Des Rosiers, C. S. Patlak, K. D. Pettigrew, O. Sakurada, and M. Shinohara (1977) The $\left[{ }^{14} \mathrm{C}\right]$ deoxyglucose method for the measurement of local cerebral glucose utilization: Theory, procedure, and normal values in the conscious and anesthetized albino rat. J. Neurochem. 28: 897-916.

Strong, R., P. Hicks, L. Hsu, R. T. Bartus, and S. J. Enna (1980) Age-related alterations in the rodent brain cholinergic system and behavior. Neurobiol. Aging 1: 59-63.

Thal, L. J., S. G. Horowitz, B. Dvorkin, and M. H. Makman (1980) Evidence for loss of brain $\left[{ }^{3} \mathrm{H}\right]$ spiroperidol and $\left[{ }^{3} \mathrm{H}\right] \mathrm{ADTN}$ binding sites in rabbit brain with aging. Brain Res. 192: 185-194.

Thierry, A. M., G. Blanc, A. Sobel, L. Stinus, and J. Glowinski (1973) Dopaminergic terminals in the rat cortex. Science 182; 499-501. 